\title{
Tradição latino-românica do Livro de Isaac: análise de lugares-críticos
}

\author{
César Nardelli Cambraia* \\ Teresa Cristina Alves de Melo \\ Cynthia Elias Leles de Vilaça
}

RESUMO: O presente trabalho tem como objetivo analisar alguns lugares-críticos que têm contribuído para o estabelecimento da relação genética entre testemunhos subsistentes da tradição latino-românica do Livro de Isaac e propor um estema guiado por esses lugares-críticos.

PALAVRAS-CHAVE: Filologia românica; crítica textual, Isaac de Nínive; Idade Média.

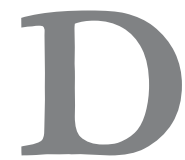

entre os diversos textos que tiveram grande circulação na Idade Média, destaca-se, no mundo românico, o chamado Livro de Isaac, obra ascética composta em fins do século VII. Trata-se de um caso especialmente interessante, porque sua circulação deixou um rastro de vários testemunhos, manuscritos e impressos, em diferentes línguas. A fim de se apresentar uma modesta contribuição para a reconstrução do percurso histórico da referida obra, discutem-se no presente trabalho ${ }^{1}$ alguns lugares-críticos que têm se demonstrado relevantes para estabelecer a relação genética entre testemunhos subsistentes de sua tradição.

\footnotetext{
Universidade Federal de Minas Gerais - nardelli@ufmg.br; Doutorandas do Programa de Pós-Graduação em Estudos Linguísticos da Universidade Federal de Minas Gerais.

1 Uma versão preliminar deste trabalho foi apresentada na VII SEVFALE, Universidade Federal de Minas Gerais, $1^{\circ}$ a 5 de outubro de 2007.
} 


\section{Livro de Isaac: autor, obra e traduções}

Como informa Cambraia (2000, p. 20), Isaac nasceu em Bet Qatraye (no atual Qatar) e foi ordenado bispo de Nínive no Mosteiro de Bet 'Abe (no norte do atual Iraque) por Jorge, o Católico, em 676 d.C. Cinco meses depois, renunciou ao cargo e foi viver como anacoreta na montanha de Matout, na região de Bet Huzaye (na atual província do Cuzistão do Irã). Posteriormente, mudou-se para o mosteiro de Rabban Shabur (também no atual Irã), onde aprofundou seus conhecimentos das Sagradas Escrituras e teria escrito suas obras por volta de 688. Morreu cego e com idade bem avançada, aproximadamente no ano de 700 , tendo sido enterrado no próprio mosteiro de Rabban Shabur.

Embora não haja consenso sobre a genuinidade de todas as obras atribuídas a Isaac de Nínive, Chialà (2002, p. 66-83) considera, com base em pesquisas mais recentes, que estariam entre as obras genuínas três conjuntos de capítulos e dois fragmentos de uma outra coleção. A Primeira Parte é composta de 82 capítulos $^{2}$; a Segunda Parte compõe-se de 41 capítulos (dos quais o $16^{\circ}$ e o $17^{\circ}$ correspondem respectivamente ao $54^{\circ}$ e ao $55^{\circ}$ da Primeira Parte); a Terceira Parte apresenta 17 capítulos (dos quais o $14^{\circ}$ e o $15^{\circ}$ correspondem respectivamente ao $22^{\circ}$ e ao $40^{\circ}$ da Primeira, e o $17^{\circ}$ corresponde ao $25^{\circ}$ da Segunda); a Quinta Parte compreende apenas dois fragmentos próprios. Vê-se que, conjuntamente, a obra de Isaac compreende pelo menos 137 capítulos distintos.

Das obras que teriam sido compostas por Isaac de Nínive, foi a chamada Primeira Parte, composta de 82 capítulos e tida como seguramente genuína (cf. Brock, 1987, p. 43; 1999-2000, p. 476), que logrou maior difusão pelo mundo. ${ }^{3}$ Tendo sido escrita originalmente em siríaco, teria sido traduzida para o grego em fins do século VIII ou princípios do século IX e, deste, para o latim por volta do século XIII [terminus ad quem] (Chialà, p. 356).

2 Brock (1986, p. 33) esclarece ainda que um capítulo presente na tradução grega impressa em 1770 é na verdade uma carta de Filoxeno a Patrício (trata-se do cap. 4 dessa tradução) e que outros quatro são textos de autoria de João da Dalyata (caps. 2, 7, 43 e 80). Desses cinco capítulos, dois circularam na tradição latino-românica: em relação aos testemunhos latinos, o cap. 2 corresponde ao cap. 43 de $L F, 23$ de $L L, 20$ de $L B, 42$ de $L V$ e 28 de $L P$; e o cap. 7 corresponde ao cap. 70 de $L F, 43$ a de $L L, 41$ de $L B, 62$ de $L V$ e 53 de $L P$ (as siglas utilizadas nesta nota para os testemunhos latinos são explicadas na seção seguinte).

3 Uma visão da amplitude de sua difusão pode ser verificada com base nas descrições da tradição dessa obra feitas por Chabot (1892, p. 54-69), Petit (1924, p. 10-11), Khalifé-Hachem (1971, col. 2041-2054), Miller (1984, p. lxxvii-cxii), Bunge (1985, p. 4-7), Cambraia (2000a, p. 21-38; 2005b), Brock (1999-2000) e Chialà (2002, p. 323-369). 


\section{Testemunhos latino-românicos do Livro de Isaac}

A tradição latino-românica do Livro de Isaac encontra-se distribuída em diversos testemunhos: até o presente momento, tem-se notícia de aproximadamente 85 testemunhos manuscritos e 18 edições impressas: 65 latinos (53 manuscritos +12 edições impressas), 4 portugueses (todos manuscritos), 3 espanhóis ( 1 manuscrito e 2 edições impressas), 3 catalães (todos manuscritos), 1 francês (manuscrito) e 27 italianos (23 manuscritos +4 edições impressas). No presente estudo, porém, são analisados 21 deles, os quais são identificados a seguir (as siglas indicam a língua e a cidade em que se encontra o manuscrito ou em que foi publicada a edição impressa): ${ }^{4}$ (a) em latim: $L F=$ cód. plut. $L X X X I X / 96$, Biblioteca Medicea Laurenziana, Florença, século XIII, fóls. [0r]-48v; $L L=\mathrm{c}$, cód. ALC. 387, Biblioteca Nacional, Lisboa, 1409, fóls. 94v-115v; LB = , Jacob Gumiel, Barcelona, 1497, fóls. 1r-151r; $L V=$, [s.n.], Veneza, 1506, fóls. 1r-49r; $L P=$, eeeed. de J.-P. Migne, Paris, 1865, cols. 811-886 / (, b) em português: PR = cód. 50-2-15, Biblioteca Nacional, Rio de Janeiro, século XV, fóls. 1r-114r; PL = cód. ALC. 461, Biblioteca Nacional, Lisboa, século XV, fóls. 14r-101v; PE = cód. CXII/1-40, Biblioteca Pública, Évora, fins do século XV, fóls. 13r-20r; $P_{2}=$ cód. ALC. 281, Biblioteca Nacional, Lisboa, século XV, fóls. 1v-2v e 45r / (c) em espanhol: $E M$ = cód. II/795, Biblioteca do Palácio Real, Madri, , 1484, fóls. 1-123r; EZ = Juan Hurus, [Zaragoza], 1489, fóls.1r-182r; ES = Ungut Meinardo \& Stanislao Polono, Sevilha, , 1497, fóls. 127v-162v / (d) em catalão: $C E=$ cód. n.I.16, Real Biblioteca do Monastério, San Lorenzo de El Escorial, séc. XV, fóls. [0r]-69r; $C S=$ cód. 5-3-42, Biblioteca Capitular Colombina, Sevilha, século XV, fóls. 1r-185r; $C B=$ cód. 148, Biblioteca Universitária, Barcelona, fins do século XVI, fóls. 78v-86v [118v-127v] / (e) em francês: FP = cód. lat. 14891, Biblioteca Nacional, Paris, século XIV, fóls. 308r-365v / (f) em italiano: $I F r=$ cód. ricc. 1489, , Biblioteca Riccardiana, Florença, séc. XIV, fóls. 1r-162r; IFp = cód. palat. 47, Biblioteca Nacional Central, Florença, século XIV, fóls. 1r-39r; $I V=$ Bonetum Locatellum, Veneza, 1500, fóls. 1r-70v; IF = Gaetano Tartini \& Santi Franchi, Florença, 1720, págs. 1-111,5 IR = Tip. dei Clasici Sacri, Roma, 1845, págs. 91-284 (vol. I) e 7-88 (vol. II). ${ }^{6}$

4 A localização do texto nos fólios dos testemunhos segue a numeração original do códice: nos casos em que há fólio anterior ao início da numeração original, atribuiu-se-lhe o número 0 .

5 Em IF, o texto de Isaac é precedido por 40 págs. com as seções Prefazione e Notiz̨ie e é sucedido por 30 págs. com as seções Tavola, Osservazioni e Approvaz̨ioni.

6 Em IR, o texto de Isaac é precedido por 82 págs. com as seções Proemio, Prefažione, Notiz̨ie e Prolegomena (vol. I) e é sucedido por 56 págs. com as seções Osservažioni e Indice (vol. II). 
Embora não haja até o presente momento nenhuma proposta para a relação genética entre todos os 21 testemunhos identificados acima, em dois estudos recentes (Cambraia, 2007b e 2007a) apresenta-se proposta respectivamente para a tradição portuguesa ${ }^{7}$ e a espanhola, ${ }^{8}$ com base na análise detalhada de diversos lugares-críticos:

\begin{tabular}{|c|c|}
\hline $\begin{array}{c}\text { Estema 1 } \\
\text { Tradicão portuguesa } \\
\text { (Cambraia, 2007b) }\end{array}$ & $\begin{array}{c}\text { Estema 2 } \\
\text { Tradicão espanhola } \\
\text { (Cambraia, 2007a) }\end{array}$ \\
\hline${ }_{P E}^{*}$ & \\
\hline${ }_{P E}^{*}$ & \\
\hline
\end{tabular}

\section{Lugares-críticos}

Dada a extensão do Livro de Isaace a copiosidade de testemunhos, qualquer tentativa de reconstruir sua tradição latino-românica exigirá necessariamente um trabalho minucioso, o que sugere que essa tarefa deva ser realizada aos poucos. Como contributo para essa reconstrução, analisam-se aqui cinco lugares-críticos já identificados como relevantes para a discussão, embora obviamente ainda não sejam suficientes para se chegar a resultados definitivos.

Para tornar o processo de reconstrução transparente e objetivo, apenas apresentam-se na presente seção os lugares-críticos, identificando as variantes genuínas. Após sua apresentação, discute-se, na seção seguinte, sua função na elaboração do estema da tradição latino-românica do Livro de Isaac.

\subsection{Continuum silentium}

O primeiro lugar-crítico é uma seção que Cambraia (2000, p. 34) assinala estar ausente em LL: trata-se de uma unidade de texto que, na tradição latina, se inicia pela seqüência continuum silentium e constitui parte genuína,

\footnotetext{
7 A propósito da tradição portuguesa, conferir também Cambraia (2000, 2002, 2003, 2004) e Menegaz (1994, 2002).

8 A propósito da tradição espanhola, consulta também Cambraia (2002) e França (2004, 2005).
} 
pois está presente na tradição siríaca (cf. cap. 38 de Wensinck (1969, p. $194-$ 195) e cap. 40 de Miller (1984, p. 203)). Sua distribuição nos testemunhos em estudo está registrada no quadro abaixo:?

Quadro 1 - Lugar-crítico continuum silentium

\begin{tabular}{|l|l|l|}
\hline LF: $\varnothing$ & PR: cap. 33 (fól. 87v14) & EM: cap. 26 (fól. 97v15) \\
LL: $\varnothing$ & PL: cap. 33 (fól. 76v1) & EZ: cap. 26 (fól. rvjv16) \\
LB: cap. 27 (fól. 114v9) & & ES: cap. 31 (fól. 150va14) \\
LV: $\varnothing$ & & \\
LP: cap. 36 (col. 866) & & \\
\hline CE: cap. 27 (fól. 51 rb25) & FP: cap. 20 (fól. 355r1 2) & IFr: $\varnothing$ \\
CS: cap. 27 (fól. 145r11) & & IFp: $\varnothing$ \\
& & IV: $\varnothing$ \\
& & IF: $\varnothing$ \\
& & IR: $\varnothing$ \\
\hline
\end{tabular}

\subsection{Fortitudinem}

O segundo lugar-crítico é uma seção que Cambraia (2000, p. 34) identificou ocorrer duas vezes na tradição portuguesa: trata-se de uma unidade de texto que, na tradição latina, começa por fortitudinem e constitui parte genuína, uma vez que consta da tradição siríaca (cf. cap. 10 de Wensinck (1969, p. 78 80) e cap. 10 de Miller (1984, p. 74-76)). Na tradição siríaca, a seção mencionada ocorre apenas uma vez e situa-se na parte inicial da obra, mas na tradição latino-românica varia sua freqüência (uma vez $\mathrm{x}$ duas vezes) e sua posição (parte inicial e/ou parte final). Sua distribuição nos testemunhos em análise aparece no quadro abaixo (I = posição inicial; e $\mathrm{F}=$ posição final) $:^{10}$

9 O lugar-crítico em questão não consta de $P L_{2}, P E$ e $C B$ em função de condição fragmentária destes.

10 O lugar-crítico em questão não consta de $P L_{2}$ e $P E$ porque não há nele excerto da seção mencionada. 
Quadro 2 - Lugar-crítico fortitudinem

\begin{tabular}{|l|c|l|}
\hline LF: F - cap. 71 (fól. 47r17) & PR: I - cap. 20 (fól. 62r2) e & EM: I - cap. 14 (fól. 69v12) \\
LL: F - cap. 42 (fól. 115r4) & F - cap. 47 (fól. 112r1) & EZ: I - cap. 14 (fól. mvijv21) \\
LB: I - cap. 14 (fól. 79v3) & PL: I - cap. 20 (fól. 61r13) e & ES: I - cap. 18 (fól. 147ra24) \\
LV: I - cap. 35 (fól. D3vb) & F - cap. 47 (fól. 96r10) & \\
LP: Ø & & \\
\hline CE: I - cap. 14 (fól. 36ra30) & FP: I - cap. 9 (fól. 343r6) & IFr: F - cap. 49 (fól. 152r12) \\
CS: I - cap. 14 (fól. 97r1)13 & & IFp: F - cap. 70 (fól. 37ra42) \\
& & IV: F - cap. 51 (fól. 67r30) \\
& IF: F - cap. 51 (pág. 109-4) \\
& IR: F - cap. 51 (vol. II, pág. 82-4) \\
\hline
\end{tabular}

Há uma diferença relevante entre $L F$ e $L L$ : embora a seção em questão esteja na parte final da obra em ambos os casos, em LF (e também em IFr, $I F p, I V$, IF e IR) constitui a penúltima seção e antecede a que se inicia por nunquam de ore, mas em LL constitui parte final da antepenúltima seção, sendo seguido pela seção que se inicia por bic est ordo sobrius e só depois pela que começa por nunquam de ore.

\subsection{Nunquam de ore}

O terceiro lugar-crítico é uma seção que Cambraia (2005, p. 11) verificou estar ausente nos testemunhos latinos $L B$ e $L P$ : trata-se de uma unidade de texto que, na tradição latina, se inicia pela seqüência nunquam de ore e que não seria genuína, pois está ausente da tradição siríaca (ocorreria como parte final do cap. 17 de Miller (1984, p. 95)). Essa seção, que aparece em testemunhos latino-românicos, constitui uma seqüência de normas de conduta ${ }^{12}$ a serem seguidas pelos monges e inclui até mesmo frase extraída dos Diálogos do Papa Gregório I (540-604), como já assinalou Cambraia (2004, p. 110-112; 2005b, p. 12-14). A distribuição da seção mencionada nos testemunhos em estudo é a seguinte: ${ }^{13}$

11 O cap. 14 de CS está mutilado no início, pois falta ao códice um fólio entre os fóls. 96 e 97.

12 Trata-se de um conjunto de frases extraídas de diferentes obras: Epistolas, de São Jerônimo (n. 22, 58, 60, 96, 108 e 125); Diálogos, de São Gregório (liv. 3, cap. 14); e Sentenças; de Santo Isidoro (liv. 2, cap. 1; liv. 3, cap. 19).

13 O lugar-crítico em questão não consta de PE porque não há nele excerto da seção mencionada. 
Quadro 3 - Lugar-crítico nunquam de ore

\begin{tabular}{|c|c|c|}
\hline $\begin{array}{l}\text { LF: cap. } 71 \text { (fól. 48r18) } \\
\text { LL: cap. } 43 \text { (fól. 115v39) } \\
\text { LB: Ø } \\
\text { LV: cap. } 63 \text { (fól. F7va) } \\
\text { LP: Ø }\end{array}$ & $\begin{array}{l}\text { PR: cap. } 48 \text { (fól. 111r20) } \\
\text { PL: cap. } 48 \text { (fól. 100v3) } \\
\text { PL: [cap. 48] (fól. 45r11) }\end{array}$ & $\begin{array}{l}E M: \varnothing \\
E Z: \varnothing \\
E S: \varnothing\end{array}$ \\
\hline $\begin{array}{l}C E: \varnothing \\
C S: \varnothing \\
C B: \varnothing\end{array}$ & FP: cap. 33 (fól. 364v 34) & $\begin{array}{l}\text { IFr: cap. } 49 \text { (fól. 155r5) } \\
\text { IFp: cap. } 70 \text { (fól. 37vb32) } \\
\text { IV: cap. } 52 \text { (fól. 68v 20) } \\
\text { IF: cap. } 51 \text { (pág. 111-6) } \\
\text { IR: cap. } 51 \text { (vol. II, pág. 86-22) }\end{array}$ \\
\hline
\end{tabular}

\subsection{Misericordiae}

O quarto lugar-crítico é uma expressão que Cambraia (2002, p. 300301) detectou variar entre a tradição portuguesa e a espanhola: trata-se da expressão de misericórdia, que na tradição latina aparece como misericordice e constitui forma genuína, já que assim aparece na tradição siríaca ocidental (cf. cap. 17 de Miller (1984, p. 95)). Nos testemunhos espanhóis, aparece em seu lugar a expressão de mirra, variante que, como proposto no trabalho acima mencionado, teria surgido da uma leitura equivocada da abreviatura latina mie, que está presente em testemunhos latinos (p. ex., $L F$ e $L L$ ). No quadro a seguir, registram-se as variantes na tradição em análise: ${ }^{14}$

\section{Quadro 4 - Lugar-crítico misericordize}

\begin{tabular}{|c|c|c|}
\hline $\begin{array}{l}\text { LF: misericonde (fól. 47r7) } \\
\text { LL: misencondie (fól. 115v32) } \\
\text { LB: mirre (fól. 148r8) } \\
\text { LV: misericordie (fól. F7rb33) } \\
\text { LP: misericordiæe (col. 8853) }\end{array}$ & $\begin{array}{l}\text { PR: de misercordia (fól. 111r4) } \\
\text { PL: de misericondia (fól. 100r13) } \\
P L_{2} \text { de misericondia (fól. 2v30) }\end{array}$ & $\begin{array}{l}\text { EM: de mirra (fól. 123r1) } \\
\text { EZ: de mirra (fól. tviijv15) } \\
\text { ES: de mirra (fól. 142vb1) }\end{array}$ \\
\hline $\begin{array}{l}\text { CE: de mirra (fól. 64vb27) } \\
\text { CS: de mjrra (fól. 184v14) } \\
\text { CB: de misericordia (fól. 80r24) }\end{array}$ & FP: de mjerre (fól. 364v20) & $\begin{array}{l}\text { IFr: dela misericordia (fól. 151v12) } \\
\text { IFp: della misericordia (fól. 38ra17) } \\
\text { IV: dela misericordia (fól. 67r11) } \\
\text { IF: della misericordia (pág. 108-22) } \\
\text { IR: della misericordia (vol. II, pág. 80-25) }\end{array}$ \\
\hline
\end{tabular}

\footnotetext{
14 O lugar-crítico em questão não consta de $P E$ em função de condição fragmentária deste.
} 


\subsection{Fertilis terra}

O quinto e último lugar-crítico é uma seção que Vilaça (2008) identificou no contraste entre os testemunhos IFr e $I V$ : trata-se de uma unidade de texto que, na tradição latina, começa por fertilis terra e constitui parte genuína, pois consta da tradição siríaca (cf. cap. 6 de Wensinck (1969, p. 56) e de Miller (1984, p. 54)). Sua distribuição nos testemunhos em análise está registrada no quadro a seguir: ${ }^{15}$

Quadro 5 - Lugar-crítico fertilis terra

\begin{tabular}{l} 
LF: Ø (fól. 11v18) \\
LL: Ø (fól. 100v7) \\
LB: Fertilis terra est... lux fulgebit (fól. 32v11) \\
LV: Fertilis terra est...lux fulgebit (fól. B5vb24) \\
LP: Ø (col. 831-5) \\
\hline PR: Bem he fecta $e$ auondosa a t<e>rra...resplandece luz muy clara (fól. 27r1) \\
PL: A alma que en temor...Resplandece lume (fól. 30r6) \\
\hline EM: Ca aquella tierra es abundosa y fertile...aquella preciosa lumbre resplandecera (fól. 29r2) \\
EZ: Ca aquella tierra es abundosa y fertile...aquella preciosa lumbre resplandecera (fól. evijr11) \\
ES: Bien es fecha buena $e$ abondosa la tierra...resplandece luz marauillosa (fól. 135va44) \\
\hline CE: Certamente aquella terra es fructuosa e abundosa...aquell precios lum resplendex (fól. 14vb13) \\
CS: Certament aquella terra es fartil...aquell precios lum resplendex (fól. 40v13) \\
FP: La terre est planteureuse...vne lumiere resplandist dedens loscurte dicelle (fól. 322r33) \\
IFr: Ø (fól. 40v13) \\
IFp: Ø (fól 9rb42) \\
IV: Quella terra e fertile...resplendera la luce (fól. 16v9) \\
IF: Ø (pág. 26-3) \\
IR: Ø (vol. I, pág.148-14)
\end{tabular}

\section{Discussão dos dados}

Para facilitar a elaboração do estema baseado nos lugares-críticos (doravante, LC) analisados aqui, convém apresentar os resultados em forma de uma matriz de variantes genuínas $(\mathrm{Y}) \times$ não-genuínas $(\mathrm{X})$, organizada por tradições e segundo o sistema adotado em Cambraia (2005a, p. 136-146):

15 O lugar-crítico em questão não consta de $P L_{2} P E$ e $C B$ em função de condição fragmentária destes.

16 Embora falte a esse testemunho a primeira frase do trecho em questão (justamente a que fala da terra fértil), a parte restante está presente. 
Quadro 6 - Matriz de variantes

\begin{tabular}{|l|c|c|c|c|c|c|c|c|c|c|c|c|c|c|c|c|c|c|c|c|c|}
\hline & LF & LL & $L B$ & $L V$ & $L P$ & $P R$ & $P L$ & $P L_{2}$ & $P E$ & $E M$ & $E Z$ & $E S$ & $C E$ & $C S$ & $C B$ & $F P$ & $I F p$ & $I F r$ & $I V$ & $I F$ & $I R$ \\
\hline LC-I & $\mathrm{X}$ & $\mathrm{X}$ & $\mathrm{Y}$ & $\mathrm{X}$ & $\mathrm{Y}$ & $\mathrm{Y}$ & $\mathrm{Y}$ & - & - & $\mathrm{Y}$ & $\mathrm{Y}$ & $\mathrm{Y}$ & $\mathrm{Y}$ & $\mathrm{Y}$ & - & $\mathrm{Y}$ & $\mathrm{X}$ & $\mathrm{X}$ & $\mathrm{X}$ & $\mathrm{X}$ & $\mathrm{X}$ \\
\hline LC-II $^{17}$ & $\mathrm{X}$ & $\mathrm{X}$ & $\mathrm{Y}$ & $\mathrm{Y}$ & $\mathrm{Z}$ & $\mathrm{X}$ & $\mathrm{X}$ & - & - & $\mathrm{Y}$ & $\mathrm{Y}$ & $\mathrm{Y}$ & $\mathrm{Y}$ & $\mathrm{Y}$ & - & $\mathrm{Y}$ & $\mathrm{X}$ & $\mathrm{X}$ & $\mathrm{X}$ & $\mathrm{X}$ & $\mathrm{X}$ \\
\hline LC-III & $\mathrm{X}$ & $\mathrm{X}$ & $\mathrm{Y}$ & $\mathrm{X}$ & $\mathrm{Y}$ & $\mathrm{X}$ & $\mathrm{X}$ & $\mathrm{X}$ & - & $\mathrm{Y}$ & $\mathrm{Y}$ & $\mathrm{Y}$ & $\mathrm{Y}$ & $\mathrm{Y}$ & - & $\mathrm{X}$ & $\mathrm{X}$ & $\mathrm{X}$ & $\mathrm{X}$ & $\mathrm{X}$ & $\mathrm{X}$ \\
\hline LC-IV & $\mathrm{Y}$ & $\mathrm{Y}$ & $\mathrm{X}$ & $\mathrm{Y}$ & $\mathrm{Y}$ & $\mathrm{Y}$ & $\mathrm{Y}$ & $\mathrm{Y}$ & - & $\mathrm{X}$ & $\mathrm{X}$ & $\mathrm{X}$ & $\mathrm{X}$ & $\mathrm{X}$ & $\mathrm{Y}$ & $\mathrm{X}$ & $\mathrm{Y}$ & $\mathrm{Y}$ & $\mathrm{Y}$ & $\mathrm{Y}$ & $\mathrm{Y}$ \\
\hline LC-V & $\mathrm{X}$ & $\mathrm{X}$ & $\mathrm{Y}$ & $\mathrm{Y}$ & $\mathrm{X}$ & $\mathrm{Y}$ & $\mathrm{Y}$ & - & - & $\mathrm{Y}$ & $\mathrm{Y}$ & $\mathrm{Y}$ & $\mathrm{Y}$ & $\mathrm{Y}$ & - & $\mathrm{Y}$ & $\mathrm{X}$ & $\mathrm{X}$ & $\mathrm{Y}$ & $\mathrm{X}$ & $\mathrm{X}$ \\
\hline
\end{tabular}

Quanto à tradição latina, a matriz acima permite estabelecer que:

(a) LF, testemunho mais antigo datável do século XIII ou XIV, não pode ser considerado o primeiro registro da tradução latina e deve ser apenas uma cópia: isso se deve ao fato de apresentar erros (cf. LC-I, LC-II, LC-III e LC-V) como ainda ao fato de nem todos esses erros estarem presentes em todos os demais testemunhos latinos analisados (não é, portanto, o arquétipo de tradição latina).

(b) $L F$ e $L L$ pertencem a um mesmo ramo da tradição latina, pois apresentam quatro erros conjuntivos (cf. LC-I, LC-II, LC-III e LC-V). Não é possível, porém, saber ainda propriamente o tipo de relação de parentesco entre eles: filiação de um ao outro ou mesma paternidade para ambos?

(c) $L F$ não pode ser cópia de $L L$, porque, além de $L F$ (século XIII ou XIV) possuir data anterior a de LL (datado de 1409), a tradução latina do Livro de Isaac parece ter sido feita na Itália (Chialà, 2000, p. 357) e LL teria sido copiado em Portugal.

(d) $L B$, de 1497, não pode derivar de $L F$ ou $L L$ por não apresentar os quatro erros conjuntivos mencionados em (a) e (b).

(e) $L V$, de 1506, apresenta dois erros conjuntivos (cf. LC-I e LC-III) em relação a $L F / L L$, mas não pode ser cópia deles em função da ausência de dois erros conjuntivos (LC-II e LC-V) presentes nestes.

(f) $L P$, de 1865, possui o erro conjuntivo do LC-V, mas não os erros dos outros testemunhos latinos: portanto, não pode derivar deles, mas deve ter algum vínculo com ramo de $L F / L L$, possivelmente como caso de contaminação. A origem de LPé, aliás, informada pelo editor (Migne, 1865, p. 811): terá sido retirado da edição de Galland, ${ }^{18}$ impressa em 1778 em Veneza (doravante, $L V_{2}$ ).

17 Como as variantes não-genuínas são diferentes, fez-se necessário o uso de mais símbolos: $\mathrm{X}=$ seção no final (penúltima posição); X' = seção no final (antepenúltima posição); X” = seção no meio e no final (antepenúltima posição); e $Z$ = seção ausente.

18 Andrea Galland, Bibliotheca veterum patrum. Venetiis: ex typ. J. B. Albritii Hieron. fil., 1765-81. (Tomo XII, 1778, p. 3-35) 
Com base nos dados acima, pode-se então elaborar o seguinte estema para representar a relação entre os testemunhos latinos:

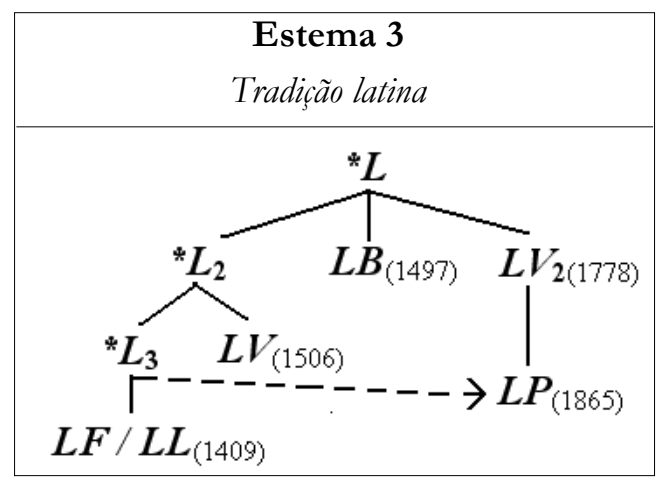

Neste estema, ${ }^{*} L_{2}$ é o testemunho que apresentaria os erros de LC-I e LC-III (presentes em $L F, L L$ e $L V$ ) e ${ }^{*} L_{3}$ é o que possuiria, além desses dois, ainda mais os erros de LC-II e LC-V (presentes em LF, LL e LP). Como $L P$ não pode estar sob $* L_{2}$ por não apresentar os erros de LC-I e LC-III nem sob $* L_{3}$ por não apresentar os erros de LC-II e LC-V, uma possível explicação para a presença de LC-V seria a contaminação de algum testemunho do ramo de $* L_{3}$ Como os dados disponíveis não permitem determinar exatamente de qual testemunho do ramo de $* L_{3} L P$ teria extraído o erro de $L C$-V, estabeleceu-se provisoriamente como fonte da contaminação o próprio testemunho ${ }^{*} L_{3}$. Caso se constate que esse erro de $L C-V$ já estava no modelo de $L P$, essa contaminação ficaria em uma posição mais alta da cadeia de transmissão de $L P\left(\right.$ como em $\left.L V_{2}\right)$.

No que diz respeito à tradição portuguesa, a existência de estudo prévio (Cambraia, 2007b) dispensa a necessidade de se lidar aqui com questões internas a ela, mas é preciso correlacioná-la com a tradição latina acima reconstituída. Comparando os dados da matriz, percebe-se que:

(a) É necessário um outro testemunho latino interposto, que apresente apenas o erro do LC-III, o único que terá passado para a tradição portuguesa de forma clara.

(b) A presença do erro de LC-II, mas de forma peculiar (com sua presença no lugar de origem e ainda repetida no final), na tradição portuguesa sugere que nela terá havido contaminação a partir de testemunhos com a seção de LC-II em antepenúltima posição, como é o caso de LL. Embora a tradição portuguesa não possa vir diretamente de $L L$ pela ausência do erro de 
LC-I, poderia tê-lo consultado também e repetido no final assim a seção que gerou o erro de LC-II.

Inserindo no estema 3 os novos dados apurados com base na tradição portuguesa, tem-se o seguinte estema:

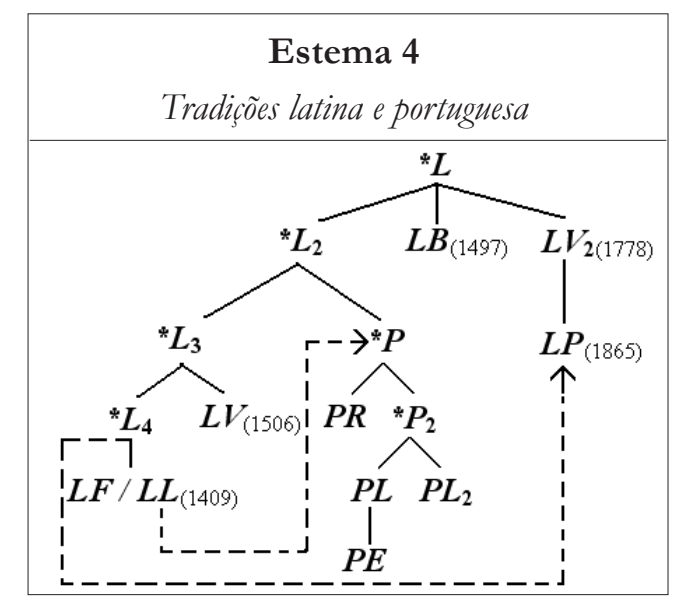

Nesse estema, ${ }^{*} L_{2}$ é o testemunho que apresentaria o erro de LC-III (presente em $L F, L L, L V, P R$ e $P L) ;{ }^{*} L_{3}$ é o que possuiria o erro de LC-I (presente em $L F, L L$ e $L V) ;{ }^{*} L_{4}$ é o que teria os erros de LC-II e LC-V e seria aquele do qual $L P$ teria extraído o erro de LC-V; e LL seria a fonte do erro com forma peculiar (a antepenúltima posição) do LC-II presente em PR e PL (por isso, remonta à forma orginal da tradição, isto é, $* P$ ).

No que tange à tradição espanhola, também o estudo prévio (Cambraia, 2007a) dispensa a discussão das relações internas, necessitando, então, que essa seja correlacionada com as tradições latina e portuguesa. A partir das informações da matriz, verifica-se que:

(a) $L B$ e $E M, E Z$ e $E S$ formam um ramo separado, definido pela presença do erro conjuntivo de LC-IV e ainda pela ausência dos demais erros.

(b) $L B$ não terá sido fonte para os espanhóis, já que esse testemunho latino foi impresso em 1497 e dois dos testemunhos espanhóis datam de antes: EM, de 1484; EZ, de 1489. Como ES foi impresso em 26 de junho de 1497 e o mês de impressão de $L B$ não é informado, resta ainda a possibilidade de $L B$ ter dado origem a ES. Entretanto, como já assinalou França (2005), os títulos de capítulo de ES estão em latim (mesmo estando o texto em si em espanhol), mas não são os mesmos de $L B$ : ora, que justificativa existiria para se usar $L B$ como modelo para a tradução em $E S$ e substituir os títulos em latim por outros igualmente em latim? A natureza dos títulos sugere que $E S$ não deriva de $L B$. 
Associando a tradição espanhola ao estema das tradições latina e portuguesa, tem-se:

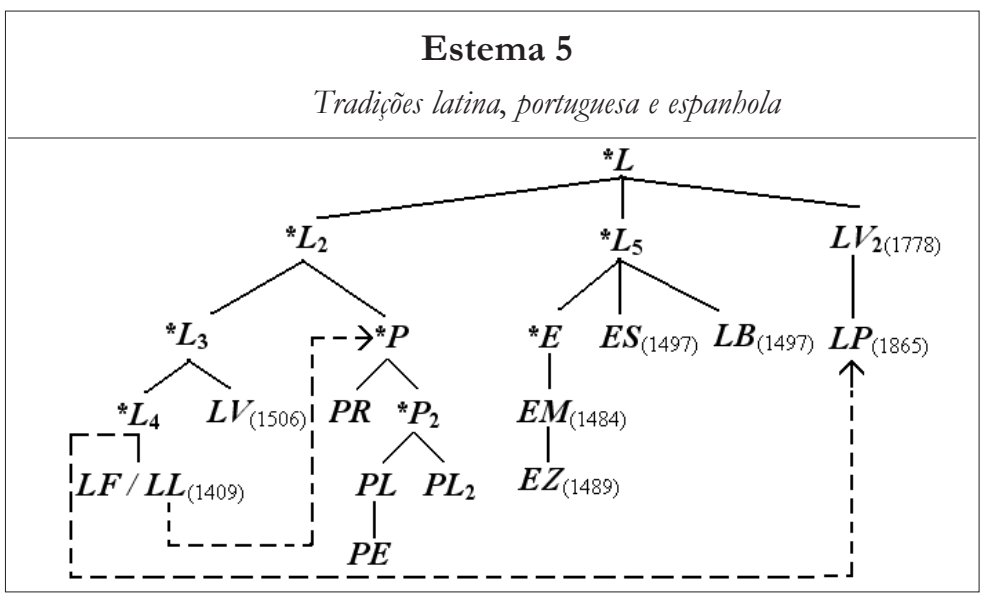

Quanto à tradição catalã, a falta de estudos prévios impede que se saiba a relação entre os testemunhos subsistentes, mas os dados da matriz permitem inferir algumas informações:

(a) CE e CS pertencem ao ramo com o erro conjuntivo de LC-IV, mas $C B$ não.

(b) A datação que se tem atribuído a CE e CS (séc. XV) sugere que não terão derivado de $L B$ (fins do séc. XV).

(c) Não se pode precisar se $C B$ deriva efetivamente de algum testemunho latino, já que sua condição fragmentária dificulta a obtenção de evidências.

Deve-se aqui acrescentar um dado novo: tanto CE (fól. 65ra23) quanto $C B$ (fól. 80v15) apresentam um apêndice com seleção de frases em catalão extraídas do Livro de Isaac, o que sugere que $C B$ tem alguma relação genética com CE, apesar de não se poder, por ora, determinar sua natureza.

Adicionando os dados provisórios da tradição catalã, tem-se o estema que se segue: 


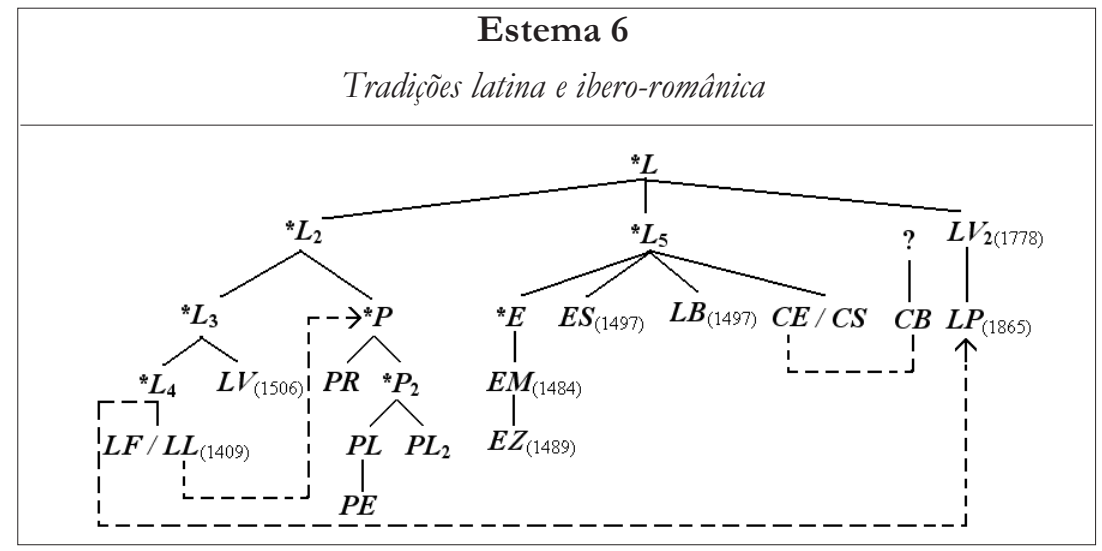

No que diz respeito à tradição francesa, representada apenas por $F P$, a matriz permite verificar que o testemunho francês apresenta o erro conjuntivo de LC-IV, o que o coloca no ramo $* L_{5}$, mas a presença também do erro de LC-III, que ocorre no ramo ${ }^{*} L_{2}$, sugere a ocorrência de mais um caso de contaminação, partindo de algum testemunho desse segundo ramo: provisoriamente poder-se-ia considerar ${ }^{*} L_{2}$ (testemunho interposto com o erro de LC-III ocupando a posição mais alta no estema e apenas com esse erro). Tem-se, assim, o seguinte estema:

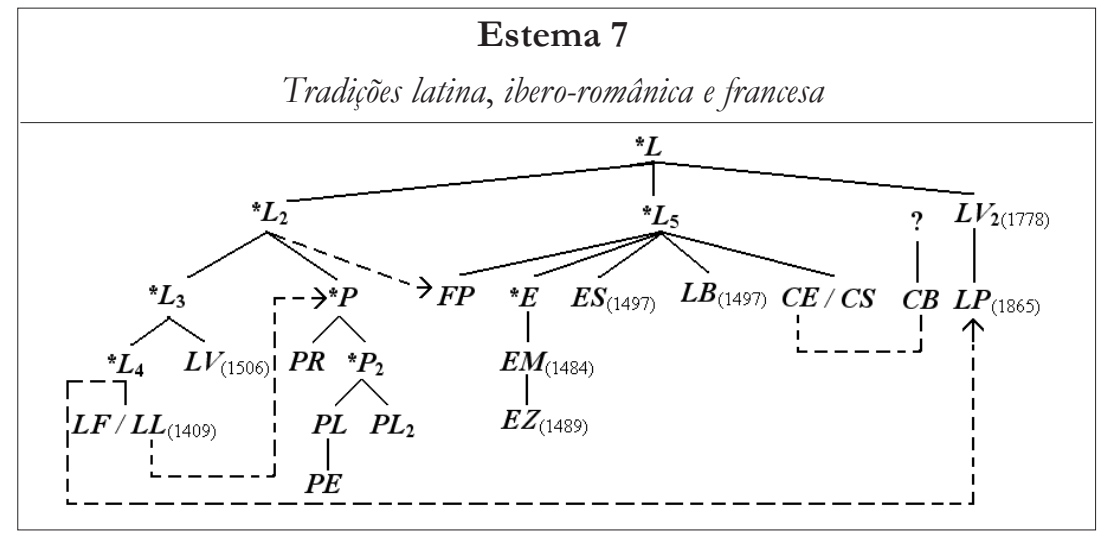

Por fim, quanto à tradição italiana, a matriz sugere que:

(a) IFp, IFr, IF e IR pertencem a um mesmo ramo, pois todos apresentam os erros conjuntivos de LC-I, LC-II, LC-III e LC-V, podendo ser subordinados a $L F$, que possui os mesmos erros. 
(b) Não é possível saber com certeza qual é a relação entre IFpe IFr, sobretudo por serem datáveis da mesma época (séc. XIV), mas a divisão em vários capítulos de IFp difere da de IFr e aproxima IFp mais de $L F$, manuscrito latino mais antigo em análise e com divisão de capítulos parecida.

(c) IV não apresenta um dos quatros erros encontrados na tradição italiana: LC-V. O vínculo de $I V$ com IFpe IFr não é claro: IV apresenta o erro de LCIII (por isso deve estar abaixo de $* L_{2}$ ), o erro de LC-I (por isso deve estar abaixo de $* L_{3}$ ) e o erro de LC-II (por isso deve estar abaixo de $* L_{4}$ ); mas, como não apresenta o erro de LC-V, presente nos demais testemunhos italianos, infere-se que deve ter havido contaminação, provavelmente de um testemunho latino, já que até o presente momento todos os testemunhos italianos analisados têm os 4 erros.

Os dados acima podem ainda ser complementados com as informações dadas pelo editor do testemunho IF (Buonaventuri, 1720, p. v-vi), que diz terem sido utilizadas sete diferentes fontes ${ }^{19}$, mas a base terá sido o chamado manuscrito Bargiacchi, aqui analisado e representado pela sigla IFr. O editor do testemunho IR (Sorio, 1845, p. 7-21) esclarece que sua edição deriva da de 1720, mas com consulta a mais três outras fontes: manuscrito Zanotti (doravante, IZ) de 1454; o impresso italiano de Veneza em 1500 (identificado no presente estudo por IV); e o impresso latino também de Veneza mas de 1506 (aqui identificado como $L V$ ).

Os dados disponíveis podem ser assim relacionados no estema tinha sido elaborado até este ponto:

19 Buonaventuri (1720, p. vi) afirma que no Vocabolario della Crusca se fala ainda de um manuscrito que terá pertencido a Mario Guiducci e depois a Cosimo Venturi, mas o referido editor, no entanto, não chegou a ver esse testemunho e duvida de sua existência. 


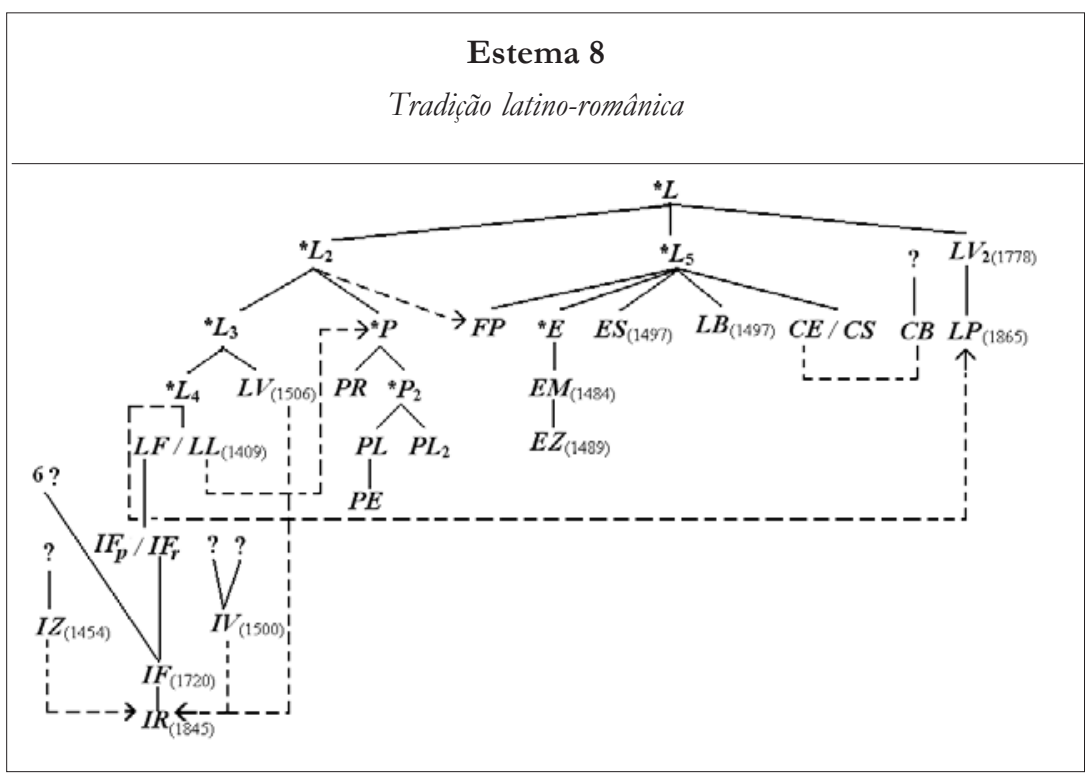

No estema acima, ${ }^{*}$ Lrepresenta a primeira tradução latina do Livro de Isaac, realizada até fins do século XIII; ${ }^{*} L_{2}$ é o testemunho que possuiria o erro de LCIII (presente em $L F, L L, L V, I F r, I F p, I V, I F, I R, P R, P L, P L$ e $F P$ [neste útimo, por contaminação]); ${ }^{*} L_{3}$ é o que possuiria o erro de LC-I (presente em $L F, L L, L V$, IFr, IFp, IV,IFe IR); ${ }^{*} L_{4}$ é o que possuiria os erros de LC-II e LC-V (presentes em $L F, L L, L P$ [neste útimo, apenas LC-V e por contaminação], PR/PL [nestes dois útimos, apenas LC-II e por contaminação a partir de LL], IFr,IFp, IV [neste útimo, apenas o LC-II pois o erro de LC-V foi corrigido por contaminação com testemunho não-identificado], $I F$ e $I R$ ); e $L_{5}$ é o que possuiria o erro de LC-IV (presente em FP, EM, EZ, ES, LB, CE e CS).

Ficam em aberto: a origem de IZ (embora naturalmente deva estar subordinado a uma tradição italiana originalmente única); a origem e localização dos seis testemunhos, além de IFr, consultados para a cópia de IF; a relação entre IFr eIFp (certamente também subordinados a uma mesma tradição italiana); a origem de IV (de uma mesma tradição italiana, mas com provável contaminação de fora dela); a relação entre $C E$ e $C S$ (certamente também subordinados a uma mesma tradição catalã); e a relação entre $C B$ e o resto da tradição catalã.

Como se vê, há indícios claros de que o processo de transmissão da tradição latino-românica do Livro de Isaac foi bastante complexo, com declarados casos de contaminação. A contaminação provavelmente não terá ocorrido apenas na tradição italiana (caso em que os editores dizem explicitamente terem consultado 
mais de uma fonte), mas também em outras em que o Livro de Isaac terá circulado em diferentes testemunhos: basta lembrar aqui que, como informa Cambraia (2007b), vinculados ao Mosteiro de Alcobaça há pelos menos três (LL, PL e $\left.P L_{2}\right)$ e que, segundo apurou Cambraia (2002, p. 298-299), na biblioteca pessoal de Cristóvão Colombo havia três (dois em latim [um exemplar de $L V$ e um outro provavelmente de LB] e um em catalão [CS]). Nota-se, portanto, que a existência de contaminação tornará sensivelmente árdua a tarefa de reconstruir a tradição latino-românica do Livro de Isaac, pois, como disse Maas (1950, p. 8), a contaminação dificulta a eliminatio (eliminação de testemunhos não-pertinentes para a reconstituição de um texto genuíno), quando não a torna impossível. Justamente em função dessa peculiaridade, o estema provisório aqui apresentado serve apenas para indicar relações de afinidade, já que o número restrito de lugares-críticos analisados não permite desembaraçar os fios das diferentes tradições que certamente se cruzaram. Assim, por exemplo, há uma notável semelhança entre os texto português de $P R$ e o espanhol de $E S$, mas a contaminação acaba gerando cisões no estema, como o posicionamento de $P R$ sob $* L_{2}$ e de $E S$ sob $* L_{5}$. Para casos tão complexos, será necessária uma abordagem que conjugue aspectos qualitativos com quantitativos.

Embora tenham sido analisados aqui apenas cinco lugares-críticos, podese considerar seguramente que se deu um passo à frente na compreensão da relação entre os testemunhos da tradição latino-românica do Livro de Isaac, unidades compósitas de um quebra-cabeça de sete séculos!

\section{Bibliografia}

BROCK, S. (1986) Isaac of Nineveh: some newly-discovered works. Sobornost: Eastern Churches Review, 8, n. 1, p. 28-33.

(1987) The syriac fathers on prayer and the spiritual life. Kalamazoo, Michigan: Cistercian Publications Inc.

(1999-2000) From Qatar to Tokyo, by way of Mar Saba: the translations of Isaac of Beth Qatraye (Isaac the Syrian). Aram, 11-12, p. 475-484.

BUNGE, G. (1985) Mar Isaak von Ninive und sein 'Buch der Gnade'. Ostkirchliche Studien, Würtzburg, 34, n. 1, p. 3-22.

CAMBRAIA, C. N. (2000) "Livro de Isaac": edição e glossário (cód. ALC. 461). São Paulo. Tese (Doutorado) "Faculdade de Filosofia, Letras e Ciências Humanas, Universidade de São Paulo. . (2002) A difusão da obra de Isaac de Nínive em línguas ibero-românicas, breve notícia das tradições portuguesa, espanhola e catalã. In: RAVETTI, G. \& ARBEX, M. (Orgs.). Performance, exilio, fronteiras, errâncias territoriais e textuais. Belo Horizonte: Faculdade de Letras da UFMG. . (2003) Reconstruindo a tradição medieval portuguesa do Livro de Isaac, estudo lingüístico comparativo das versões existentes. In: MIRET, F. S. (ed.) Actas del XXIII Congreso Internacional de Lingüistica y Filologia Románica, Salamanca, 24-30 septiembre 2001. Tübingen: Max Niemeyer, v. IV. 
(2004) A circulação do Livro de Isaac em Portugal. Filologia e Lingüistica Portuguesa, 6, p. 101-114.

(2005a) Introdução à crítica textual. São Paulo: Martins Fontes.

(2005b) Contributo ao estudo da tradição latina do Livro de Isaac o cód. ALC 387 da Biblioteca Nacional de Lisboa. Scripta Pbilologica, 1, p. 6-19.

- (2007a) Tradição em língua espanhola do Livro de Isaac. Comunicação apresentada no II Congresso Virtual do Departamento de Literaturas Românicas: Edição de Textos, na Universidade de Lisboa, em Lisboa. 16 a 20 de abril de 2007.

. (2007b) Tradição em língua portuguesa do Livro de Isaac. Caligrama, 12, p. 171-204.

CHIALÀ, S. (2002) Dall'ascesi eremitica alla misericordia infinita: ricerche su Isaaco di Ninive e la sua fortuna. Firenze: Leo S. Olschki.

FRANÇA, C. S. (2004) Edição e estudo lingüistico das traducõoes em linguas românicas do tratado ascético medieval "Livro de Isaac": subsidios para o estudo da tradição espanbola. Belo Horizonte: Núcleo de Estudos de Crítica Textual da Faculdade de Letras da UFMG. (Relatório Final de Pesquisa de Iniciação Científica).

FRANÇA, C. S. (2005) Edição e estudo lingüistico das traduçoes em línguas românicas do tratado ascético medieval "Livro de Isaac": contributo para a reconstrução da tradição espanbola. Belo Horizonte: Núcleo de Estudos de Crítica Textual da Faculdade de Letras da UFMG. (Relatório Final de Pesquisa de Iniciação Científica).

MAAS, P. (1950) Textkritik. 2. ed. Leipzig: B.C. Teubner.

MELO, T. C. A de. (em preparação) "Livre d'Isaac Abbé de Syrie" (cód. lat. 14891 da BNF): edição e glossário. Belo Horizonte. Tese (Doutorado) “Faculdade de Letras, Universidade Federal de Minhas Gerais.

MENEGAZ, R. (Ed.) (1994) Livro de Isaac de Nínive (séc. XV). Rio de Janeiro: Fundação Biblioteca Nacional. 384.

(2002) O Livro de Isaac. de Alcobaça à Biblioteca Nacional. Convergência Lusiada, 19, p. 377-

MIGNE, J.-P. (1865) Patrologiae cursus completus. Series Graeca. Paris: Ed. de l'Auteur, t. 86a.

MILLER, D. (Tr.) (1984) The ascetical homilies of St. Isaac the Syrian. Trad. Dana Miller. Boston: The Holy Transfiguration Monastery.

VILAÇA, C. E. de L. (2004). Edição e estudo lingüístico das traduções em línguas românicas do tratado ascético medieval "Livro de Isaac": subsídios para o estudo da tradição italiana. Belo Horizonte: Núcleo de Estudos de Crítica Textual da Faculdade de Letras da UFMG. (Relatório Final de Pesquisa de Iniciação Científica).

(2008). "Libro del Abate Isaac di Siria" (cód. ricc. 1489 da BRF): edição e estudo comparativo com a edição princeps de 1500. Belo Horizonte. Dissertação (Mestrado) "Faculdade de Letras, Universidade Federal de Minhas Gerais.

(em preparação) "Libro del Abate Isaac di Siria": edição e glossário. Belo Horizonte. Tese (Doutorado) "Faculdade de Letras, Universidade Federal de Minhas Gerais.

WENSINCK, A. J. (1923) Mystic treatises by Isaac of Nineveh. Reimpr. Amsterdam: Koninklijke Akademie van Wetenschappen. [Reimpr, Wiesbaden: Martin Sändig oHG., 1969]

ABSTRACT: The aim of this paper is to analyze some loci critici which have contributed to the establishment of the genetic relationships between the remaining testimonies of the latinromance tradition of the Livro de Isaac and propose a stemma based on these loci critici.

KEYWORDS: Romance philology; textual criticism; Isaac of Nineveh; Middle Ages. 